\title{
Comunicación para el diálogo político e intercultural. Derecho a la comunicación y ciudadanía comunicacional ${ }^{*}$
}

\section{Communication for the political and intercultural dialogue. The right to communication and communicational citizenship}

\author{
Washington Uranga \\ Periodista, docente e investigador de la comunicación. \\ Director de la Maestría en Comunicación Institucional de la Universidad Nacional de San Luis (Argentina). \\ Contacto: wuranga@wuranga.com.ar
}

Artículo de reflexión

Fecha de recepción: abril 20 de 2015 • Fecha de aprobación: mayo 11 de 2015

"Lo que digo no lo digo como chacarero sabiondo, ni como payador leído, lo digo buscando con ustedes. Lo digo buscando, porque solo los ignorantes creen que la verdad es definitiva y maciza, cuando apenas es provisoria y gelatinosa" José Mujica

\section{RESUMEN}

El texto hace una reflexión sobre las diferentes nociones de cultura y cómo a partir de ella se generan distintas construcciones de identidad, originando un diálogo intercultural. Dicho diálogo y la comunicación son herramientas clave para apuntar a una construcción política y un intercambio de saberes por parte de los sujetos sociales, que reconozca sus derechos desde las diferencias culturales.

Palabras clave: diversidad, diálogo, comunicación, interculturalidad, ciudadanía.

* Una versión abreviada de este texto fue presentada en el congreso internacional "Comunicación, ciudadanía y paz en los objetivos del milenio", Saltillo (México), 19.03.2015

1 Palabras pronunciadas por el expresidente de Uruguay, José Mujica, en un encuentro con los intelectuales celebrado en Montevideo el 29 de abril del 2009. 


\begin{abstract}
The text reflects on the different notions of culture and how from it different constructions of identity are generated, resulting in an intercultural dialogue. This dialogue, as well as communication, are key tools to target to a political construction and exchange of knowledge by social subjects, which recognizes their rights from cultural differences.
\end{abstract}

Keywords: diversity, dialogue, communication, intercultural, citizenship.

Afirmar que los seres humanos somos diferentes unos de los otros, que somos heterogéneos, es una obviedad. Tan evidente como que el reconocimiento y la construcción de identidades conlleva también determinadas luchas por la reafirmación de lo propio que, en muchos casos, termina segregando, expulsando. Nuestras prácticas no suelen ser consecuentes con el principio de alteridad, que sostiene la autonomía del otro y de la otra y concluye que es precisamente la diferencia la que permite el enriquecimiento mutuo. Es cierto que la divergencia es un asunto presente en el quehacer diario, pero no solemos hacernos cargo de las consecuencias que ello tiene en la práctica cotidiana y en la historia de nuestras comunidades, de nuestros pueblos. Es más, las diferencias se constituyen en permanente motivo de enfrentamientos que conmueven nuestra vida hasta llegar a niveles de violencia que nos cargan de tensiones y de angustia.

Comprender el sentido de la relación entre diferentes exige asumir que las diferencias y la diversidad cultural son construcciones socio históricas de los actores y los grupos sociales, y que el diálogo intercultural se concreta en el marco de la conflictividad social, es un proceso turbulento y complejo que pone en juego la lucha de identidades. Allí quedan en evidencia las pretensiones de dominio de las distintas comunidades, grupos y actores sociales. La mayor parte de las veces, este es también un proceso que termina siendo violento, en lo simbólico seguramente y, en no pocos casos, en lo físico.

Paulo Freire (2002) sostenía que "la lucha por la unidad en la diversidad" es una disputa política que demanda "la movilización y la organización de las fuerzas 
culturales" en búsqueda de ampliar, profundizar y superar "la democracia puramente liberal". La afirmación, tomada del libro "Pedagogía de la esperanza", sigue teniendo hoy la misma fuerza que cuando se publicó en su primera edición de 1992. El diálogo entre sujetos, actores y culturas solo puede darse como consecuencia de una construcción política, económica, social y cultural de la que todos y todas somos co-autores y, a la vez, responsables. Sin perder de vista que el diálogo entre culturas genera y se vive en medio de una tensión creativa y productiva, fruto de la diferencia y de la búsqueda de la multiculturalidad, entendida esta como la convivencia justa, armónica y equilibrada entre culturas, que nunca alcanza un grado de estabilidad y de consolidación, sino que se recrea a cada instante en el marco de lo cotidiano. Es la tensión que genera la interculturalidad como utopía, con todo lo que ello tiene, a la vez, de dinamización de la acción y de angustia de lo inacabado.

El mismo Paulo Freire asegura que:

La multiculturalidad no se construye en la yuxtaposición de las culturas, mucho menos en el poder exacerbado de una sobre las otras, sino en la libertad conquistada, en el derecho asegurado a moverse, cada cultura con respecto a la otra, corriendo libremente el riesgo de ser diferente, sin miedo de ser diferente, de ser cada una 'para sí', único modo como se hace posible que crezcan juntas, y no en la experiencia de la tensión permanente provocada por el todopoderosismo de una sobre las demás, privadas de ser. La tensión necesaria permanente entre las culturas en la multiculturalidad es de otra naturaleza. Es la tensión a la cual se exponen por ser diferentes en las relaciones democráticas en que se vinculan. Es la tensión de la cual no pueden huir por estar construyendo, creando, produciendo a cada paso la propia multiculturalidad, que jamás estará lista y acabada. La tensión, por lo tanto, en este caso es la del inacabamiento que se reconoce como razón de ser de la propia búsqueda, y la de conflictos no antagónicos; no la creada por el miedo, por la prepotencia, por el 'cansancio existencial', por la 'anestesia histórica' o por la venganza que estalla por la desesperación frente a la injusticia que parece perpetuarse (2002, p. 149). 
Solo hay multiculturalidad a partir del respeto de las identidades y el reconocimiento de la diferencia. Solo hay multiculturalidad genuina en la alteridad y en el crecimiento armónico de todas las culturas en el escenario colectivo.

Y frente a las dificultades que presenta un escenario multicultural y diverso, también atravesado por tensiones, la palabra "diálogo" aparece casi como una receta que pretende ser bálsamo, por una parte, y solución mágica, por otra. En muchos casos la propuesta del diálogo se presenta desprovista de métodos que lo hagan posible, de mediaciones que lo concreten, de iniciativas que, superando lo meramente declarativo, aporten caminos posibles y viables. Del mismo modo podemos señalar que son tan frecuentes y excesivas las afirmaciones sobre la "necesidad" del diálogo que llegan a abrumarnos y hasta nos hacen perder el sentido de lo que ello realmente significa. Pero tantas declaraciones formales a favor del diálogo se ven despiadadamente derrotadas por la infinita cantidad de actitudes y prácticas que, en lo privado, en lo público y en los ámbitos nacionales e internacionales, obstruyen la posibilidad del diálogo como una alternativa concreta y una propuesta que, reconociendo las diferencias, construya instancias superadoras de encuentro en la diversidad. El diálogo necesita menos declamaciones y más acciones que lo pongan en práctica, menos agentes publicitarios y más militantes de la causa más importante: el ser humano gozando de derechos humanos en plenitud.

Frente a la crisis, a la violencia, ante la incertidumbre, pero también en el camino de la búsqueda de mejor calidad de vida, los hombres y las mujeres exteriorizan sus necesidades de encuentro, de intercambio. Aunque esto no lleve siempre a las coincidencias. Diálogo es comunicación, es construcción colectiva, es espacio de intercambio. Muchas veces de concertación y otras tantas de lucha, de debate. El diálogo es necesario, pero demanda que se construyan las condiciones para el mismo. Y, sobre todo, que no se pretenda caer en la simplificación de que diálogo es sinónimo de acuerdos, de coincidencias, de falta de tensiones. El diálogo es una actitud, una disposición y no un resultado. Y se da siempre en el contexto de una sociedad mediada por las tensiones, las diferencias y los juegos de poder.

Sería erróneo, y una dificultad importante para encontrar alternativas superadoras, situar las posibilidades del diálogo entre las culturas simplemente en la voluntad 
y/o capacidad de los actores para generar ámbitos de encuentro y puntos en común que permitan progresar hacia el entendimiento, las aproximaciones o las zonas de coincidencia. En primer lugar, porque nadie debería presuponer que la condición o el reaseguro del diálogo está puesto en lo común. El diálogo es una necesidad del ser social del hombre. Pero para su concreción efectiva requiere una actitud abierta a la escucha que no significa renunciar a la identidad y a la defensa de las propias ideas. Exige, no obstante, que los interlocutores actores sociales y/o individuos- abandonen la pretensión de ser exponentes de la única verdad o de poseer la totalidad de la misma. Al diálogo si es genuino y de buena voluntad-se ingresa sin condiciones pero no sin pre conceptos y certezas que nacen en la constitución histórica de los sujetos sociales y forman parte de los rasgos identitarios de los mismos. De allí que cuando hablamos de diálogo entre culturas partimos del reconocimiento de las identidades propias y, por lo tanto, asumimos la diferencia como dato y como valor.

El diálogo entre culturas es una relación enmarcada en el escenario del conflicto surgido de la diversidad cultural que genera intereses contrapuestos. Se evidencian juegos de poder e intentos de dominio de una cultura sobre la otra. Cada uno de nosotros y de nosotras "mira" el mundo, lo interpreta, desde las marcas y las categorías de la propia cultura. "Los hombres valoramos siempre, y lo hacemos desde la cultura en que nos hominizamos. Permanentemente juzgamos a los otros hombres y las otras culturas desde el punto de vista de la nuestra, que fácilmente damos por indiscutible y universal” (Langon, 2006, p. 74). Por lo tanto el diálogo entre culturas requiere, necesaria e inevitablemente, una tarea de construcción política que va más allá de la simple manifestación de voluntades. Política entendida como relación entre actores en el marco de la sociedad y como estrategia destinada a ponderar intereses y necesidades, para alcanzar la vigencia de la justicia y la libertad en todos sus aspectos. Así comprendido el diálogo de las culturas está estrechamente relacionado con la vigencia de los derechos económicos, sociales y culturales de los pueblos, las comunidades, los actores sociales y los individuos. Es decir, con los derechos humanos.

El diálogo intercultural se concreta en el marco de la conflictividad social. Es un proceso turbulento y complejo que pone en juego la lucha de identidades. Allí quedan en evidencia las pretensiones de dominio de las distintas comunidades, grupos y actores sociales. 


\section{LAS CULTURAS COMO LUGAR DE IDENTIDAD}

El sujeto es y se reconoce como tal, en el marco de una cultura determinada así no tenga conciencia expresa y manifiesta de ello. Para entender esta situación es necesario quitarle a la cultura la solemnidad de las definiciones y de los recorridos académicos. Las culturas son, ni más ni menos, que los ámbitos cercanos y próximos, que en lo cotidiano van estableciendo las normas de convivencia, los criterios éticos y morales, los modos de relacionamiento entre los sujetos y hasta los gustos y las preferencias. La cultura es la historia de un pueblo, pero es también el barrio, la vecindad, la fiesta, el grupo juvenil, la religiosidad y la familia. Es la identidad del sujeto y de los grupos sociales; es, al mismo tiempo, el espacio de búsqueda de esa identidad. En este tiempo marcado por las migraciones, los paraguayos, los peruanos o los bolivianos que viven en el gran conglomerado urbano de Buenos Aires o los mexicanos, caribeños y centroamericanos que viven en Estados Unidos, se identifican por sus culturas originarias, pero al mismo tiempo encuentran en ese ámbito un espacio para construir una nueva identidad, que no reniega totalmente de la anterior pero que es nueva, que busca autoafirmarse y es, a la vez, una manera de demandar reconocimiento. Porque como decíamos en otro momento, la identidad cultural se construye siempre en relación a otros y a otras.

La cultura es necesariamente un territorio. Cada vez menos territorio físico o geográficamente delimitado y cada vez más territorio simbólico. A ello ha contribuido también el desarrollo tecnológico y de los sistemas de comunicación. Hoy la cultura juvenil está cada día más próxima y asociada con la tecnología, las redes y los lenguajes de la comunicación. En ese ámbito los jóvenes desarrollan lenguajes que facilitan sus intercambios y a la vez establecen límites para el acceso de los "no iniciados". Es una búsqueda de identidad, de reconocimiento en lo individual y en lo social. En la medida en que estos espacios culturales se consolidan y se afianzan, se transforman también en espacios de poder. Desde allí se interpela, se busca incidir, se pretende influir. Espacio de poder que se manifiesta no solo en el hacia fuera, porque busca trasladar e influir con sus propias categorías a los otros ámbitos, sino también en el hacia dentro porque marca, genera identidades y establece fronteras que dificultan o impiden el acceso de quienes "no pertenecen". 
La fiesta, la celebración, el rito y las liturgias, son parte esencial del territorio y de la identidad. No hay identidad cultural sin fiesta, que es manifestación de la pertenencia y de la celebración del encuentro. Los ritos son los tatuajes de la cultura. Basta observar el comportamiento de las llamadas "tribus urbanas" o "tribus juveniles", pero también de las comunidades de migrantes, los grupos religiosos o las comunidades originarias.

El territorio cultural, físico o simbólico, otorga ciudadanía cultural a la vez que determina las condiciones de pertenencia, las atribuciones y los pactos de convivencia. Toda pretensión de diálogo entre culturas debe partir de este reconocimiento, porque de lo contrario la comunicación es imposible. Estos procesos de diálogo entre culturas requieren de la construcción de historias comunes y ritos de aproximación; el trabajo en común y las fiestas compartidas suelen ser parte de estos caminos de acercamiento entre culturas, también los espacios religiosos. En el caso del trabajo porque lo que unifica es la necesidad de la complementariedad y de la labor colaborativa para la sobrevivencia. En los otros dos porque no hay lugar para la competencia, la fiesta siempre es celebración del encuentro y se relegan (no se superan... pero se posponen) las disputas. En la religión las diferencias se diluyen en la evocación a un ser superior a quien todos los actores reconocen como punto de referencia y de unidad, aún cuando esas evocaciones sean diferentes y hasta con expresiones rituales distintas.

Nada de lo dicho niega que, en el ámbito de cada cultura, existen también luchas de poder porque hay una disputa constante entre individuos y subgrupos para imponer, desde la identidad misma, las formas de ver y entender el mundo y la relación con los otros.

\section{LAS CULTURAS EN LA VIDA COTIDIANA}

El diálogo entre culturas es una demanda y una necesidad en cada una de nuestras sociedades nacionales: por razones étnicas, de constitución de nuevos conglomerados, por motivos económicos, de edad, religiosos, migratorios o de otro orden. Surgen nuevos lenguajes en la comunicación y se renuevan los existentes. Es necesario 
avanzar en la comprensión de la nueva gramática de los medios y en la interpretación de lenguajes, sentidos y procesos de comunicación.

El diálogo entre culturas es parte de la vida cotidiana y para hablar de ello es necesario hacer referencia a actores concretos, a sujetos históricos, colectivos e individuos. Son estos actores, cuya identidad es siempre un proceso en construcción, los hacedores o no del diálogo al que aspiramos. No existen las culturas en abstracto. Lo anterior se refleja en dos importantes planteamientos que Giménez (2007), ha expuesto de modo frecuente en los últimos años: "no existen actores sin cultura ni cultura sin actores" y "antes que en los objetos y las cosas la cultura está en las personas".

Pero el mundo social es, esencial e inevitablemente, intersubjetivo. La identidad del sujeto se define en relación al otro, permitiendo al individuo percibirse a sí mismo y reconocer al otro como un distinto, otro diferente. Y a través de la intersubjetividad se pueden distinguir y reconocer realidades y fenómenos que escapan al conocimiento propio, porque el sujeto no puede percibir su experiencia inmediata pero sí puede dar cuenta de las prácticas de otros a los que reconoce como parte de la vida cotidiana y del mundo social que lo circunda. Esta construcción intersubjetiva es la que habilita el diálogo entre culturas, porque permite al sujeto ponerse "en el lugar del otro" a partir de lo que conoce de su interlocutor, ese "otro" con quien comparte el espacio social.

Las acciones que cada persona realiza están cargadas de significados. Tales acciones al ser leídas o interpretadas por otros adquieren un determinado sentido aunque nosotros mismos no hayamos tenido la intención de significar algo. Toda acción comunica, pero no existe una única interpretación de las vivencias y experiencias; estas varían según la perspectiva desde la que sean interpretadas, esto es, según el aquí y el ahora que experimenta el sujeto y en virtud del entorno que lo contextualiza.

Partiendo de la base de que los procesos culturales son esencialmente colectivos, no debería perderse de vista el campo de las transformaciones individuales en el marco de lo colectivo. Estos cambios individuales son también componentes de lo colectivo pero se constituyen de manera diversa y trascienden lo racional, para incorporar de manera sustancial lo sensible, lo afectivo y lo corporal. Estos aspectos inciden de manera fundamental en el hacer de cada individuo y se reflejan en la 
socialización que este hace en el espacio colectivo. En otras palabras: es necesario pensar al individuo, su sensibilidad y su corporeidad, como parte de la constitución de los sujetos colectivos y de la cultura. De no hacerlo estaremos perdiendo no solo el aporte rico e irrepetible de cada persona, sino que estaremos vaciando lo colectivo de la diversidad de contribuciones que provienen de las trayectorias personales, únicas y siempre originales. Los grupos juveniles o "tribus urbanas" adquieren una identidad a la que aportan todos sus integrantes desde su singularidad. Pero en este proceso no se anulan, sino que por el contrario se potencian los rasgos y las características propias de cada individuo. Lo colectivo y lo individual interactúan permanentemente para incidirse de manera mutua.

Un estereotipo frecuente cuando se menciona el tema del diálogo entre culturas es imaginar que este es un capítulo reservado al intercambio entre comunidades esencialmente diferentes, con historias y trayectorias claramente disímiles. El diálogo intercultural sería, en ese caso, el que se da entre las comunidades originarias de nuestra América y las poblaciones surgidas del mestizaje occidentalizado resultado de la irrupción colonial. No suele hablarse en cambio de diálogo de culturas cuando hay que referirse a las nuevas culturas juveniles que emergen en nuestras sociedades urbanizadas, a las culturas de la pobreza y de la marginalidad, ambas en diálogo y conflicto permanente con otras expresiones culturales surgidas del consumo y de la opulencia. Tampoco a las más habituales de nuestro tiempo: las que surgen de las cada vez más frecuentes oleadas migratorias, resultados de la pobreza, el hambre, las guerras o de la violencia social y política. En todas esas realidades hay también modos de intercambio y de conflicto entre culturas, entendidas estas como lugar de identidad de los sujetos. El diálogo en este caso adquiere las características propias de la lucha por la supremacía de un modelo sobre otro e incluso la violencia para la eliminación o aniquilamiento del diferente. Curiosamente esta confrontación, que es también una manera de dialogar, adquiere el carácter simbólico de "lucha por la seguridad", "contra la violencia" o "por la defensa de los valores tradicionales", sin advertir que lo que está en crisis en realidad son las instituciones o las formas tradicionales de organización social, política y religiosa.

En el ámbito de la vida cotidiana, el diálogo intercultural toma la forma de lucha simbólica y material por el poder, la construcción y consolidación de la hegemonía. 
En la mayoría de nuestras sociedades capitalistas, se vive en permanente tensión intercultural que impide el diálogo en los términos señalados antes en este mismo trabajo, porque se trata de una tensión generada por la realidad de la exclusión de muchos y de la falta de acceso a los derechos económicos, políticos, sociales y culturales. No puede haber diálogo sin alteridad, es decir, sin reconocimiento del otro como diferente y valorado a partir de su identidad desigual. No puede haber diálogo cuando el propósito manifiesto de cualquiera de las partes es la exclusión y marginación de las otras, su dominación y subordinación. No puede haber diálogo sin la disposición manifiesta de buscar la justicia en un contexto de plena vigencia de derechos. Porque el diálogo es comunicación de vida y no se puede construir sobre cualquier tipo de muerte.

En el caso de las culturas juveniles, potenciadas por la crisis de las instituciones (la política, la escuela, la religión, etc.), las mayores dificultades se ponen de manifiesto porque la emergencia de nuevos discursos y de diferentes maneras de entender y explicar el mundo, son leídas como amenazas por las culturas aún dominantes y por aquellos sujetos que, siendo referentes de las mismas, pugnan por no ceder los espacios de poder que todavía mantienen.

\section{IDENTIDADES Y PROCESOS DE COMUNICACIÓN}

Como bien lo sostiene la investigadora cubana Maritza García Alonso (2002), las identidades se construyen mediante procesos de comunicación entre identidades culturales distintas. La cultura puede entenderse como el resultado de procesos comunicativos entre identidades culturales que se relacionan y se entrecruzan. Es también la consecuencia de intersubjetividades que dialogan en el ámbito de lo cotidiano.

La identidad no es un hecho dado o automático. La identidad es necesariamente procesual. Y esto no es ajeno al dato de la desigualdad que establecen los sistemas sociales y que se ha implantado en América Latina y el Caribe desde el momento mismo del hecho histórico mal denominado "descubrimiento". Realidad que se multiplica por el llamado fenómeno de la globalización potenciado por el vertiginoso desarrollo de la tecnología de las comunicaciones y que ha pretendido la extensión 
planetaria de la cultura llamada "occidental", más precisamente descripta si decimos que se trata de la cultura de consumo del modelo capitalista hegemónico en el mundo.

En este contexto mundial dominado por el "relato único" se hace difícil la persistencia de la diversidad cultural. Se produce un avasallamiento permanente, por ejercicio del poder, de las culturas y de las identidades propias. Este proceso, que es de dominación y no de diálogo, se da por sustracción de la palabra, por imposición del idioma ${ }^{2}$, mediante la construcción de imaginarios tan fascinadores como inalcanzables y por la seducción mediática a través del manejo de la imagen y de la información. De allí también, tal como hemos afirmado antes, que no se puede desvincular este análisis de la problemática del poder y la dominación, particularmente si estamos hablando desde esta parte del mundo.

La identidad cultural tampoco es ontológica. La identidad siempre es una realidad que se construye en relación. Estamos hablando de comunidades humanas en relación. "Nadie puede ser, sin la presencia del otro, y nadie alcanza la afirmación de su existencia sin la capacidad de encuentro comunicativo con el semejante, el que intrínsecamente es distinto. La afirmación del ser que se expone al semejante da lugar a la apertura del pluralismo", afirma el investigador y comunicador boliviano José Luis Aguirre Alvis (2006, p. 33).

Podemos decir que la riqueza cultural del mundo es su diversidad dialogante. Lo distinto, lo diverso, lo diferente es un tesoro que estamos poniendo en riesgo cada día por el avasallamiento y la imposición de unas culturas sobre otras. Porque cada cultura se nutre de sus propias raíces, pero solo se desarrolla en contacto con las demás culturas y muere cuando está impedida de ser y manifestarse desde lo esencial de su identidad. Y estas muertes son siempre muertes atravesadas por la resistencia,

2 "Tres de cada cuatro páginas de Internet son en inglés y el setenta y dos por ciento de todos los contenidos de la Web están en inglés. El otro veintiocho por ciento se encuentra dividido entre los doce idiomas restantes, ninguno de los cuales sobrepasa el siete por ciento. Esto significa que noventa por ciento de las 6000 lenguas del mundo no están representadas en Internet. Como resulta evidente, la predominancia de contenidos en inglés excluye, de facto, a un gran número de usuarios que no hablan este idioma. De esa manera se genera una nueva forma de brecha o de desigualdad, pues los logros obtenidos a través del aumento del acceso formal a Internet de poco o nada sirven si quienes acceden no pueden comprender ni utilizar la información y el conocimiento allí contenidos" (Saffon, M. 2007). 
por la violencia que genera la impotencia, dejando marcas de rencores y odios que se extienden por generaciones.

El ser social en América Latina y el Caribe es multi-identitario. Por historia y por realidad contemporánea; se construye mediante la acumulación de capas geológicas que se superponen sin mezclarse; pocas logran penetrar en las otras generando procesos de integración cultural. Asistimos en cambio a situaciones más cercanas al avasallamiento que al diálogo intercultural creativo y productivo. Competencia entre iguales, desconocimiento o ignorancia del diferente, y dominación de los más poderosos sobre los carentes de poder. Sin diálogo intercultural, que es el proceso de comunicación de valores y saberes, se profundizan las realidades de exclusión y de marginación. Los excluidos no son solamente "explotados" sino "sobrantes" y "desechables".

Pero no caeremos en la mirada ingenua, las identidades culturales y los procesos de diálogo intercultural no pueden mirarse y analizarse al margen de las relaciones de poder, de las dominaciones económicas, políticas y sociales. Son los actores sociales, los hombres y las mujeres, quienes sufren la dominación; esta es integral, atraviesa las culturas y está en las culturas, también porque las marcas de la dominación están en el seno de las culturas dominadas.

El diálogo entre culturas, que es una reivindicación y una lucha, se apoya en los derechos económicos sociales y culturales. Solo la vigencia de los derechos humanos permitirá la existencia de un auténtico diálogo entre culturas, que sea creativo, productivo y generador de más humanidad para todos y para todas. Sin imposiciones de ningún tipo: ni económicas, ni sociales, ni políticas, ni religiosas. El diálogo entre culturas solo es posible en la vigencia plena de los derechos humanos y de la libertad de los actores sociales, de los pueblos, las comunidades y las personas.

¿Qué hacemos entonces con quienes no aceptan esta mirada de derechos? Aquí se abren otros capítulos. Tenemos que pensar acerca de la responsabilidad de la sociedad y del Estado para garantizar, a través de la educación, de la formación política y de la comunicación, una base de principios mínimos indispensables para la convivencia social. Los derechos humanos son la Carta Magna de nuestra convivencia en sociedad. 
Por ese motivo son principios irrenunciables en los que todos y todas deben ser formados y educados.

\section{El ESPACiO PÚBlico Y EL Diálogo ENTRE LAS CULTURAS}

La información y la producción de conocimiento introducen modificaciones en la realidad económica, en los procesos de producción industrial y de generación de conocimiento. Los avances de la digitalización y las nuevas tecnologías de la información y la comunicación aceleran todos los cambios anteriores, modifican de forma sustancial el escenario y abren nuevas expectativas y desafíos. Vinculado a lo anterior, surgen nuevos lenguajes en la comunicación y se renuevan los existentes. Es necesario avanzar en la comprensión de la nueva gramática de los medios y en la interpretación de lenguajes, sentidos y procesos de comunicación.

La comunicación no puede ser entendida ni como transmisión de información ni como producción de contenidos únicamente. Es esto y mucho más. Es un proceso complejo de intercambio de significados y producción de sentidos, que se organiza a modo de estrategias de comunicación generadas por los distintos actores sociales, atendiendo a sus intereses $y$ posibilidades. Estos procesos son simultáneamente culturales, religiosos, sociales, económicos y políticos. Ninguno de estos aspectos es autónomo y cada uno de ellos es interdependiente del otro.

En este contexto lo que se denomina espacio público es un lugar esencialmente comunicacional que se transforma día a día en el ámbito de lucha simbólica por el poder en la sociedad. La hegemonía del poder no es solamente institucional, sino que es al mismo tiempo, y en muchos casos, primordialmente simbólica y cultural. Lo anterior se pone en evidencia en campos tan distintos como la religión, el arte, la publicidad y el desarrollo tecnológico aplicado a la comunicación, pero fundamentalmente en la política y en la economía. Grave es la concentración de la propiedad de los medios de comunicación en grandes y poderosos grupos multimediales lo que restringe la pluralidad de voces y limita la posibilidad de que las miradas diversas se expandan en el espacio público. En palabras de Germán Rey (2010): 
"el paradigma del reforzamiento económico de las comunicaciones y su expansión global, unido a la fragilidad de las propuestas públicas y los retrocesos de la intervención y la capacidad de juego de los Estados nacionales, parece ser ya no solo un 'pensamiento único', sino una 'realidad única'. Como lo han señalado (...) los teóricos de la globalización, la comunicación es a la vez estímulo pero también 'lugar' de la construcción de sociedades-mundo.”

Hay también grupos que apuntan a generar identidades cerradas sobre sí mismas, que confunden resistencia y defensa de lo propio con aislamiento y marginación. Los guetos de cualquier tipo son un obstáculo para la construcción colectiva y para el diálogo entre culturas. No pocas organizaciones sociales, movimientos, comunidades religiosas y grupos étnicos caen en esta tentación y terminan aislándose de la participación, de los debates y de la construcción social y política a nivel nacional y regional.

Vivimos en una sociedad "mediatizada", las afirmaciones de Gomes (2015) permiten un mejor acercamiento al tema con el precepto de que:

"la mediatización comprende dos movimientos simultáneos y dialécticos. Por una parte, ella es fruto y consecuencia de relaciones, interrelaciones, conexiones e interconexiones de la utilización por la sociedad de los medios e instrumentos comunicacionales, potenciados por la tecnología digital. Por otra, ella significa un nuevo ambiente social que incide profundamente en esas mismas relaciones, interrelaciones, conexiones e interconexiones que construyen la sociedad contemporánea ${ }^{3}$.”

Teniendo en cuenta lo anterior hay que entender el espacio público, la "esfera pública” en términos de Habermas, como un territorio con una gramática propia, la que impone la comunicación moderna. Esta gramática, que no es la de todas las culturas que coexisten en ese espacio, es también una forma de imposición por “alfabetización” cultural. Son las culturas dominantes las que imponen el lenguaje, la gramática, el idioma. Cada dos semanas desaparece una lengua de las seis mil que existen en todo el mundo, situación que nos lleva a una progresión alarmante

3 Original portugués. Traducción del autor. 
respecto de la dominación cultural por vía de la lengua ${ }^{4}$. Esta es una de las batallas culturales contemporáneas. Sin modificación del escenario actual de los medios, sin cambios en el espacio público, no hay posibilidades de diálogo intercultural creativo y productivo. Precisamente porque ese espacio público no respeta una cuestión fundamental: la vigencia plena de los derechos. En principio no hay allí ejercicio del derecho a la comunicación, deteriorando la situación, tampoco rigen los derechos económicos, políticos, sociales y culturales en forma plena.

\section{COMUNICACIÓN Y CIUDADANÍA}

Morin (2010, p. 47) sostiene que "el problema universal de todo ciudadano" es "cómo conseguir acceso a las informaciones sobre el mundo y cómo adquirir la posibilidad de articularlas y organizarlas". Pero para hacerlo, para "reconocer y conocer" los problemas del mundo "hace falta una reforma del pensamiento" que requiere de la "contextualización" y "complejización" del conocimiento". Esto es exactamente lo contrario a lo que discursivamente construye hoy el sistema de medios: la simplificación, las descontextualización y la fragmentación. El discurso mediático, entendiendo por ello la trama que envuelve información y entretenimiento, opera como un mecanismo distorsivo y obstaculizador respecto de la comprensión de lo real. Muestran... pero impiden comprender.

Siguiendo el pensamiento de Morin diremos que para comprender lo que pasa es necesario recuperar el pensamiento complejo. Entender que, a contramano de la lógica que nos ofrecen los medios de comunicación, todas las situaciones son multicausales y que no existe una sola causa para un solo efecto. Por otro lado García Canclini (2014, pp. 16-17) sostiene que "la sociedad es un laberinto de estrategias". Y que, por lo tanto, "conocer es atravesar abismos: cuando una disciplina se asoma a otra, cuando los habitantes de una nación se desplazan, cuando la escritura en papel

4 (...) de las 6.000 lenguas existentes en el mundo, más de la mitad corren el riesgo de desaparecer arrasadas por la ola tecnológica. Se calcula que cada dos semanas desaparece una lengua y que, en el período de un siglo, aproximadamente el noventa por ciento de las lenguas podrían haber desaparecido. Como tal, la ausencia de pluralidad y de protección a la diversidad cultural no se presentaría únicamente en las NTIC, sino que terminaría reproduciéndose en la totalidad de las esferas sociales. Saffon, M. P. (2007). 
se mira desde lo digital". Para comprender hay que rehacer las preguntas y para ello es necesario formularlas desde lugares distintos y simultáneamente para que se entrecrucen en la vida cotidiana, en las ciencias y en las disciplinas.

El concepto de ciudadanía se asocia, en primer lugar a un estado (status) basado en la facultad de una persona de ser acreedora y tributaria de derechos y deberes, en tanto y en cuanto es considerada miembro pleno de una comunidad (Marshall y Bottomore, 1998, pp. 22 y ss).

La ciudadanía implica un sentido de pertenencia, integración y membrecía a una determinada comunidad política, entre cuyos integrantes se establecen relaciones de interdependencia, responsabilidad, solidaridad y lealtad. Pero la ciudadanía plena demanda voluntad positiva, disposición a la participación, interés por los asuntos comunes (asuntos públicos). La condición ciudadana se construye también con formación y voluntad política, es decir, con la decisión del individuo de participar, y se alcanza mediante el reconocimiento por parte de la comunidad política a la que se pertenece. Pero la idea básica de ciudadanía se ha ido vaciando de sentido hasta perder gran parte de su significación para la vida cotidiana de las personas, quedando así reducida a la mera cuestión jurídica y al ejercicio del voto para la elección de los representantes. Existe el riesgo de confundir o identificar la ciudadanía solo con beneficios tales como la libertad de expresión o seguros sociales, que si bien son parte, no agotan la condición ciudadana.

Hay todavía una tarea pendiente para revisar la noción de ciudadanía con el fin de desterrar una concepción meramente pasiva y formal y avanzar hacia un concepto que incluya a la vez derechos y responsabilidades que son inherentes a la condición ciudadana y que permita promover una ciudadanía social, activa y participante.

Información y ciudadanía tienen una relación esencial. El acceso a la información por parte de los ciudadanos es una condición para el discernimiento, para la construcción de opiniones fundadas y, de esta manera, para el ejercicio pleno de la ciudadanía. La calidad de la participación aumenta en relación directa con la calidad de la información que se posee. El derecho de acceso a la información no es una cuestión 
de los periodistas, de los profesionales o los técnicos. Es una cuestión ciudadana, un derecho que nos asiste a todos en tanto y cuanto ciudadanos.

De la misma manera el derecho a la comunicación debe ser comprendido como un derecho habilitante de otros derechos. Nadie puede demandar algo que no conoce o que no percibe como un derecho. Y el derecho a la comunicación solo se puede comprender y puede ser ejercido efectivamente en el marco de cada cultura, partiendo de sus valores y de sus modos de entender, de entenderse y de cómo las personas se constituyen en ese espacio. Mantenerlo en vigencia es una tarea cultural pero inevitablemente política y asociada a la idea de cambio, motorizada por los sueños y las utopías de los sujetos que la llevan adelante y cuyos éxitos no se miden exclusivamente por las metas alcanzadas sino por los procesos a través de los cuales las personas, los ciudadanos y ciudadanas, adquieren mayores capacidades y posibilidades para comunicar y comunicarse.

La práctica de la comunicación requiere responsabilidad de quienes ejercen la comunicación en los medios para asegurar información pertinente, oportuna y veraz, que incluye el imperativo de contextualizar, evitando dar la parte como si fuera el todo y dejando de lado los golpes de efecto producidos mediante el sensacionalismo; por parte de los gobernantes para asegurar que el derecho a la comunicación y la libertad de expresión se cimienten en la igualdad de oportunidades y de los actores sociales en asumir que ejercer el derecho a la comunicación supone tomar la iniciativa, involucrarse y poner en juego la palabra para hacer diciendo.

Así planteada, la comunicación puede ayudar a la gobernabilidad y a la paz, cualquier desbalanceo puede ser nefasto para la democracia. Desde este punto de vista, siendo importantes las normas serán siempre insuficientes. En materia de comunicación y gobernabilidad, la responsabilidad de los actores se ubica incluso por encima del cumplimiento estricto de las normas. Hay que construir también un capítulo de responsabilidad social de la comunicación con base ética y cimentada en una perspectiva de derechos. 


\section{Ciudadanía comunicacional}

Vale entonces preguntarse si existe una "ciudadanía comunicacional" y si es aceptable utilizar semejante concepto. La ciudadanía hoy supone comunicación, porque lo ciudadano se construye desde el diálogo público en el espacio público, en una interacción creativa que es multiactoral y multisectorial. No se puede pensar lo público sin la comunicación y los comunicadores tienen que asumir como propia la tarea de la construcción ciudadana en su integralidad poniendo sobre sus espaldas el compromiso de acompañar, apuntalar y enriquecer desde sus saberes específicos a los procesos ciudadanos innovadores.

Martín-Barbero sostiene que:

Pensar la política desde la comunicación significa poner en primer plano los ingredientes simbólicos e imaginarios presentes en el proceso de formación del poder. Lo que deriva la democratización de la sociedad hacia un trabajo en la propia trama cultural y comunicativa de las prácticas políticas. Ni la productividad social de la política es separable de las batallas que se libran en el terreno simbólico, ni el carácter participativo de la democracia es hoy real por fuera de la escena pública que construye la comunicación masiva (2002, p. 222).

Lo anterior supone trabajar por la promoción del debate público dentro de un modelo comunicacional que busca la creación y mantenimiento de redes de diálogo y producción simbólica. Se trata de definir una comunicación que sea centro de la creación y el mantenimiento de lo público en el sentido más constructivo, generando y promoviendo intereses, espacios e imágenes comunes, que garanticen una democracia culturalmente vivida, es decir, asumida como valor y práctica. Una comunicación que cree y recree lo público en relación con sus públicos ciudadanos. Una comunicación que incorpore al sujeto popular a la comunicación pública en el espacio público. En fin, una comunicación que interpele al poder y ayude al surgimiento de nuevas relaciones y otros equilibrios que favorezcan y empoderen al ciudadano como protagonista de la vida política. 
Se trata, en definitiva, de construir una ciudadanía comunicacional que contemple, por una parte, la oferta mediática (desde los medios hacia el público-ciudadano) y, por otra, el consumo cultural (de las audiencias-ciudadanas hacia los medios).

Estamos hablando entonces de "ciudadanía comunicacional que, en el marco de los procesos políticos y culturales, permita la participación creativa y protagónica de las personas como forma de eliminar la concentración de poder de cualquier tipo para, así, construir y consolidar nuevas democracias", tal como lo propuso el congreso de comunicadores latinoamericanos y caribeños reunidos en Porto Alegre (Mutirão de comunicação América Latina y Caribe, 2010).

Tal ciudadanía comunicacional no puede ejercerse sino en el espacio público entendido como el escenario del consenso y del conflicto, de la lucha, la negociación y el diálogo. Pero al mismo tiempo, una ciudadanía comunicacional así entendida es, sin duda, un aporte indispensable para construir una cultura de paz cimentada en un proceso de intercambio y producción de sentidos en la sociedad que también es inexcusablemente, un espacio de disputa simbólica y material. Pese a su complejidad el espacio público es el único ámbito válido para dirimir las disputas que son propias y a la vez genuinas de la construcción democrática en diversidad, pluralidad y diferencia. Para eso se necesita garantizar el derecho ciudadano a la comunicación.

\section{Participación sociocultural Plena: CAMINo hacia la PAZ}

Somos comunicadores y comunicadoras comprometidos con la construcción de una sociedad más justa, equitativa y solidaria, siendo así el compromiso debería ser trabajar por la construcción de una relación sociocultural plena entre actores sociales, comunidades y pueblos.

¿Qué se entiende por una relación sociocultural plena?

Los procesos comunicacionales que hagan posible el intercambio equitativo, el diálogo entre actores sociales, civilizaciones, culturas y pueblos, basados en la mutua comprensión, respeto y en la igual dignidad de las culturas. La comunicación 
contribuye a la identidad porque, a partir de recuperar lo propio, facilita el diálogo con otras realidades para el enriquecimiento mutuo. La comunicación permite la construcción de una identidad abierta al diálogo que colabora para superar el agotamiento de la construcción meramente endógena.

Tales procesos, basados en la plena vigencia de los derechos humanos son la condición sine qua non para la construcción de la cohesión social, de la reconciliación entre los pueblos y de la paz entre las naciones.

Solo es posible reconstruir la amistad social, que podemos llamar también fraternidad y que hoy está gravemente dañada por el atropello de los derechos fundamentales, si nos hacemos mutuamente responsables los unos de los otros, respetando los derechos y las identidades de cada uno y cada una a partir del reconocimiento y la valoración mutua.

Para seguir con las preguntas ¿Es esta tan solo una actitud individual?, ciertamente no lo es. Es individual, es personal, porque si los individuos no cambian los colectivos no se modifican, pero es ante todo una actitud política, porque se construye colectivamente a partir del vínculo en común. Esta construcción necesita de actitudes, procesos y estrategias de comunicación. Esta construcción se hace también, y fundamentalmente, desde la comunicación.

En América Latina y el Caribe, estos procesos comunicacionales en el diálogo intercultural son fundamentales para la gobernabilidad democrática, factor de entendimiento y de respeto entre personas; instrumento para exponer propuestas, compartir conocimientos, despejar dudas, aprender y enseñar; la comunicación supera a todas las tecnologías y medios que la facilitan y se convierte en la marca característica del ciudadano, del ser humano y de todo espacio democrático y respetuoso de los demás.

Amistad social es sinónimo de solidaridad. Y, tal como lo afirma Reguillo (2015), solidaridad es “ponerse en el lugar del otro", es "ponerse en los zapatos del otro". De ahí la necesidad de que "miremos nuestros pies y nuestro calzado y preguntémonos todos juntos, cuántos zapatos soy capaz de calzar para caminar con otros”. 
¿Mirada ingenua? Es posible. Mirada utópica, me atrevería a decir. Y preguntarnos tal como lo hace el uruguayo Eduardo Galeano: “¿para qué sirve la utopía?”. Y respondernos con sus propias palabras: "La utopía está en el horizonte. Camino dos pasos, ella se aleja dos pasos y el horizonte se corre diez pasos más allá. ¿Entonces para qué sirve la utopía? Para eso, sirve para caminar."

\section{¿QUÉ HACER?}

Planteada esta pregunta la tarea siempre parece abrumadora. Sin embargo, lo más conducente es pensar en lo que puede hacer cada uno y una de nosotros y nosotras. Lo que está a nuestro alcance, aquello que es próximo, viable y factible. Luego será el paso de organizar todo ello en estrategias que multipliquen los esfuerzos y amplíen los resultados.

Citando de nuevo al escritor uruguayo Eduardo Galeano (2013), podemos decir que

Son cosas chiquitas. No acaban con la pobreza, no nos sacan del subdesarrollo, no socializan los medios de producción y de cambio, no expropian las cuevas de Alí Babá. Pero quizá desencadenen la alegría de hacer, y la traduzcan en actos. Y al fin y al cabo, actuar sobre la realidad y cambiarla, aunque sea un poquito, es la única manera de probar que la realidad es transformable.

Propongámonos entonces algunas "cosas chiquitas". Que sean tareas que nos muevan a la alegría de hacer y seguramente, ese paso a paso, nos permitirá demostrarnos a nosotros mismos y a los demás, que la tarea del cambio, de la libertad y de la vigencia de los derechos es posible desde la comunicación y en el diálogo entre las culturas.

Sin pretensión de inventario estas son algunas de las tareas:

\section{Liberar la palabra}

Esta debería ser nuestra preocupación y tarea central. Sobre todo teniendo en cuenta que vivimos es un continente marcado culturalmente por la tradición oral. Es 
necesario asumir la tradición de la lengua, rescatar nuestra diversidad lingüística y desencadenar la palabra.

Esto se logra ante todo fomentando las tradiciones culturales, la música, el canto, la literatura, la poesía. Desarrollando estrategias para que nuestros artistas y nuestros escritores tengan condiciones para acceder a los grandes públicos y los mercados masivos, dando las batallas en los circuitos comerciales ya conocidos, pero también generando ámbitos de consumo cultural alternativo sin que esto se confunda con lo marginal.

Desencadenar la palabra es desarrollar estrategias para la emergencia de otros y otras voces, para la irrupción de otras estéticas, para la producción de bienes culturales nacidos de la diversidad de culturas presentes en América Latina y el Caribe. Las culturas tienen que hablar por sí mismas y tenemos que hablar desde y hacia a las culturas.

Esto requiere estrategias de gestión cultural, de mecanismos de producción e industrias culturales que implicarán negociaciones con el Estado para el establecimiento de políticas públicas e inversiones en materia de cultura y comunicación.

\section{Desarrollar la escucha}

Sin escucha atenta no hay palabra potente. Paulo Freire (2002, p. 151) ha sostenido que "aceptar y respetar la diferencia es una de esas virtudes sin las cuales la escucha no se puede dar". La actitud de escucha está unida a la aceptación de la diferencia como un valor en la sociedad, en la vida en comunidad.

Pero la actitud de escucha tiene que ser trabajada como una virtud que, sin embargo, es reiteradamente menospreciada por los factores de poder de la sociedad actual.

No se trata solamente de escuchar, sino de saber escuchar poniéndose en los zapatos del otro, intentando comprender las circunstancias, la historia que lleva a la constitución identitaria del hablante que está frente a nosotros. Escuchar es hacerlo desde el otro, desde la otra, respetando al interlocutor como otro totalmente otro y distinto que me enriquece a partir de la diferencia. 


\section{Generar y garantizar espacios y condiciones para el diálogo intercultural}

El diálogo intercultural se asegura de manera primordial en el espacio público que es un espacio mediatizado. Esto requiere de estrategias destinadas a multiplicar los medios y los productos de comunicación desde una perspectiva integral de derechos y de diálogo intercultural.

Aunque una de las alternativas puede ser garantizar medios y productos a las comunidades e identidades culturales, no parece ser esta la única iniciativa. El diálogo intercultural tiene que atravesar todo el espacio público, desde los medios identificados con las diferentes comunidades, pero sobre todo a través de la interculturalidad transversal.

Y si bien el espacio público está mediatizado por la garantía de acceso se construye también, y fundamentalmente, desde otros ámbitos vinculados con la palabra liberada, desencadenada. Es necesario promover la producción cultural desde las identidades a través de la generación de imágenes, de la música, de la producción artística y de la información. Es una tarea política, económica, organizativa y comunicacional.

\section{Producir bienes culturales desde una perspectiva de derechos}

La enunciación de los derechos tiene que ser plasmada por la puesta en acción de los mismos; la integridad de estos debe traducirse en bienes culturales (películas, videos, puestas de teatro, libros, mensajes a través de televisoras, radios, medios impresos, recursos de Internet, etc.) que expresen los valores, anhelos, sueños y deseos presentes en los actores sociales que animan nuestra diversidad cultural.

Esto supone también revisar, revalorizar y sistematizar las categorías interpretativas, científicas, éticas y morales presentes en nuestras diferentes culturas para incorporarlas de manera crítica, reflexiva y dialogante como recurso y riqueza propia de la producción científica latinoamericana y caribeña. 
Es un llamado a subvertir lo establecido desde la creatividad de todos y todas, pero en particular de los jóvenes, atendiendo a sus miradas, a sus preguntas, sus interrogantes, sus nuevas formas de construcción y también a sus rebeldías y desenfados.

\section{Crear, promover y desarrollar observatorios y auditorias de comunicación}

Revisando la experiencia que ya existe en materia de observatorios y auditorias sociales y ciudadanas de la comunicación, resulta necesario multiplicar este tipo de iniciativas, reforzarlas y desarrollarlas en red.

El propósito fundamental de esta acción es incidir, desde una perspectiva de derechos en la calidad de la comunicación, de los productos culturales y en el mejoramiento de la agenda pública, generando al mismo tiempo bases para producir nuevos criterios destinados a la elaboración de políticas públicas de cultura y comunicación. Es una tarea de alcance científico, de producción de metodologías y categorías analíticas, con consecuencias e intenciones de incidencia política.

\section{Desarrollar estrategias integrales de comunicación}

Asumir como responsabilidad de las organizaciones, las instituciones académicas, las empresas y los medios comprometidos con la comunicación desde una perspectiva de derechos, la tarea de desarrollar estrategias integrales de comunicación que, inspiradas en el derecho a la comunicación como derecho humano fundamental, aporten soluciones prácticas y operativas para garantizar la palabra, producir mensajes diversos y plurales, hacer viable y factible la gestión de bienes culturales desde el campo popular e incidir en políticas públicas de comunicación y cultura.

Tales estrategias integrales tienen que contemplar las condiciones de producción en la diversidad, de gestión industrial y económica, de distribución masiva de los bienes culturales producidos y los procesos de evaluación que todo ello demande para que, mediante una revisión crítica de lo realizado, se puedan encontrar alternativas superadoras. 


\section{Construir y consolidar ciudadanía comunicacional}

Desarrollar, de manera sistemática, los espacios de comunicación ciudadana que aseguren la relación entre grupos, comunidades, sectores y organizaciones sociales. Todos estos son actores privilegiados de la comunicación y su participación en la comunicación ciudadana debería ser una de las claves de lectura para entender que se está garantizando de manera efectiva el derecho a la comunicación. Hay que trabajar para consolidar un concepto de ciudadanía comunicacional que, lejos de la concepción liberal de la ciudadanía, nos hable de compromiso y vocación de construcción de espacios de participación en toda la sociedad a partir del desarrollo de espacios de comunicación, de la utilización de todos los lenguajes y las tecnologías.

Probablemente esta iniciativa nos llevará también a redefinir el sentido de lo alternativo y comunitario en el marco de estrategias complejas de comunicación, pensando en lo macro y lo micro de manera articulada y en la generación de políticas públicas que contemplen todas las dimensiones de manera integral.

La propuesta de ciudadanía comunicacional debería revisar las experiencias de periodismo cívico, periodismo social, también los aportes de la economía política de la comunicación, y de manera muy particular buscar los caminos para que tanto los nuevos desarrollos tecnológicos en materia de comunicación, como las conclusiones que se van obteniendo de la práctica de las redes sociales, se incorporen dentro de esta perspectiva comunicacional. Todo ello con la intención de poner a los grupos marginados y excluidos en el centro de nuestra preocupación para devolverles la palabra sustraída, empoderando su discurso y desarrollando sus capacidades comunicativas mediante procesos de formación.

\section{COMUNICADORES: FACILITADORES DEL DIÁLOGO PÚBLICO}

Todas estas tareas deben ser realizadas teniendo en cuenta que la sociedad actual, por diversa y fragmentada, nos invita y nos obliga a trabajar siempre con la mirada puesta en el reconocimiento de las diferencias y en el marco del conflicto que ello genera. Conflicto entendido no como mero enfrentamiento, sino como la manifestación 
palpable de lo distinto, de la confrontación de prácticas y perspectivas teóricas. Frente a esta realidad el conflicto puede ser fuente de enfrentamientos estériles o canalizarse mediante procesos de comunicación hacia la producción creativa de alternativas siempre superadoras, aunque las mismas no concluyan necesariamente (como decíamos al comienzo) en consensos. Seguir dialogando desde la diferencia es reconocer la alteridad como un valor. Hoy por hoy es una riqueza que debemos rescatar en nuestras sociedades.

El anhelo mayor es encontrar los caminos para desarrollar todo lo anterior asumiendo que esa construcción debe darse en una sociedad inevitablemente atravesada por las diferencias y los conflictos. Para ello, a los comunicadores y a las comunicadoras nos cabe la responsabilidad de ser facilitadores del diálogo público entre diferentes, en un espacio público atravesado por la conflictividad. Convertidos en hacedores del diálogo en la diversidad, sin renunciar al compromiso con la vigencia de los derechos humanos y la defensa de los excluidos y marginados en todo sentido, estaremos construyendo las bases de una solidaridad genuina como camino hacia una paz auténtica y sustentable.

Todo lo dicho, por supuesto, no es más que un aporte a nuestro proceso de construcción colectiva.

Abrí con palabras de José Mujica, el expresidente de Uruguay, y quiero cerrar también con una cita suya que expresa el espíritu de mi presentación: "La buena fe es nuestra única intransigencia. Casi todo lo demás es negociable” ${ }^{5}$.

5 Mujica, op. cit. 


\section{REFERENCIAS}

Aguirre, A. J. (2006). La otredad y el derecho a la comunicación desde la alteridad. La Paz: Azul Editores.

Freire, P. (2002). Pedagogía de la esperanza. Un reencuentro con la Pedagogía del oprimido. Buenos Aires: Siglo veintiuno editores.

Galeano, E. (2013). Al fin y al cabo, somos lo que hacemos para cambiar lo que somos. Recuperado de http://eduardo-galeano.blogspot.com.ar/2013/07/al-fin-y-al-cabo-somoslo-que-hacemos.html

García, A. M. (2002). Identidad cultural e investigación. La Habana: Centro de Investigación y de Desarrollo de la Cultura Cubana Juan Marinello.

García Canclini, N. (2014). Un mundo entero como lugar extraño. Buenos Aires: Gedisa.

Giménez, G. (2007). Estudios sobre la cultura y las identidades sociales. México

Gomes, P. (2015). Midiatização da sociedade: Uma primeira opinião, en Fausto, N. A. (et. al). (2015). Relatos de investigaciones sobre mediatizaciones. (e-book). Argentina: Editorial de la UN de Rosario.

Langon, M. (2006). "Diversidad cultural una idea a tener en cuenta para educar", en Ameigeiras, A. y Jure, E. (comp.) (2010). Diversidad cultural e interculturalidad. Prometeo Libros.

Marshall, T. H. y Bottomore, T. (1998). Ciudadanía y clase social, (v. original 1950), Madrid: Alianza, Trad. P. Linares.

Martín-Barbero, J., y Martín, M. B. (2002). Oficio de cartógrafo: travesías latinoamericanas de la comunicación en la cultura. Santiago de Chile: Fondo de Cultura Económica.

Morin, E. (2010). ¿¿Hacia el abismo? Globalización en el siglo XXI. Barcelona: Paidos 
Mutirão de comunicação América Latina y Caribe. (2010). Carta de Porto Alegre. [En línea]. Recuperado de http://www.muticom.org.br.

Reguillo, R. (2015). Globalizar la solidaridad: palabra, escucha y acción. [En línea]. Recuperado de http://viaductosur.blogspot.mx/2015/03/globalizar-la-solidaridad-palabra.html

Rey, G. (2010). Las políticas comunicativas de nueva generación y sus efectos. Entre el pensamiento único y las posibilidades de diversidad. Conferencia dictada en el Foro Universidad Santiago de Compostela, España.

Saffon, M. P. (2007). El derecho a la comunicación: un derecho emergente. [En línea]. Recuperado de http://comunicaacionyciudadania.blogspot.com.ar/2007/08/el-derecho-la comunicacin-un-derecho.html 